\title{
COMMENTARY
}

\section{Validating scores: a good business for a trauma register}

\author{
Marcus R Raum* \\ See related research by Brockamp et al., http://ccforum.com/content/16/4/R129
}

\begin{abstract}
Acute hemorrhage after life-threatening injury is still one of the main killers after trauma. The article by Brockamp and colleagues presents a good overview of recent scores for estimation of blood loss and transfusion requirement.
\end{abstract}

In Brockamp and colleagues' article, six different scores for estimating and handling severe blood loss are described and compared with each other: the TraumaAssociated Severe Hemorrhage score, the Prince of Wales Hospital/Rainer score, the Vandromme score, the Assessment of Blood Consumption/Nunez score, the Schreiber score and the Larsen score [1].

The management of severe bleeding is important to avoid early death after trauma. The triangle of death concept has been introduced to remind caregivers of the strong interaction between acidosis, coagulopathy and hypothermia during hemorrhagic shock [2]. Acute bleeding is a known high-risk factor for mortality after trauma. Consequently it is important for any caregiver to be adequately informed about the severity of injury of multiple trauma patients as fast as possible. Scoring systems can be used for course evaluation, quality assessment, standard definitions, economy, patient selection/ triage and evaluation of the decision process [3].

A score that may indicate the chance of mortality shortly after admission can be useful to become aware of the severity of trauma and may influence further therapeutic decisions [4]. Several scoring systems for mortality risk have been developed for trauma patients $[5,6]$. The most used and common trauma scores - such as the Injury Severity Score, the New Injury Severity Score, the Revised Trauma Score and the Trauma Injury

*Correspondence: marcus.raum@helios-kliniken.de

Department of Traumatology/Orthopedic Surgery, Helios Clinic Siegburg, Ringstraße 49, 53721 Siegburg, Germany
Severity Score - depend on acquirement of knowledge of all anatomical injuries [7-11]. None of these scores, however, include the risk of severe blood loss after trauma!

The Revised Trauma Score uses physiological parameters, so it can in principle be determined early in the emergency room and even in the ambulance and might be helpful to estimate mortality risk after trauma [12]. However, calculating the original Revised Trauma Score is not trivial and will typically require computer support. Furthermore, the inclusion of the breathing frequency by the original and simplified Revised Trauma Score is problematic since this parameter is both observer dependent and treatment dependent, especially in ventilated patients. Additionally, statistical analyses of the Revised Trauma Score showed a poor correlation with mortality [13]. And, as already mentioned, the risk of severe blood loss is not part of the Revised Trauma Score.

Severe blood loss is a life-threatening situation after trauma [14]. Following advanced trauma life support principles, stopping the bleeding is the most important step after airway management [15]. Transient responders after resuscitation are especially difficult to manage. With less clinical experience in the emergency room, special scoring systems might be helpful to give a quick overview of the state of the patient. But which score should be used? Brockamp and colleagues give us a good summary of four civilian and two military systems to predict the risk of massive transfusion at a very early stage after trauma [1].

The authors used the German TraumaRegister DGU [16] to evaluate different existing scores. The registry prospectively records comprehensive data (more than 350 items) for all severely injured patients who were admitted alive to the emergency room. Extensive information from the scene of the accident up to discharge from the hospital is documented on four sheets. Sheet A describes the patients' situation at the scene of the accident as recorded by ambulance personnel, Sheet B upon arrival in the emergency room, Sheet $C$ upon arrival in the ICU and Sheet D at discharge from the hospital with all diagnoses and operations. Major 
complications, organ failure and hospital mortality are also recorded in the registry.

The registry contains data for more than 56,000 severely injured patients. These data provide a fantastic opportunity to test different scores on a trauma population from Western Europe. Answers could therefore be given to questions nobody has yet been able to resolve.

Data from these registries also have disadvantages that always should be kept in mind. The quality of a register depends on complete and correct data. Unfortunately the lack of complete data is an ongoing problem. Based on this problem, only 5,147 of 56,573 patients had complete data for the analysis in this article. This is sad because so much worthy information for so many patients cannot be used.

On the contrary, it will be hard to find another trauma register with so many patients to work with. In my opinion, the TraumaRegister $\mathrm{DGU}^{\odot}$ is an excellent tool for answering these kinds of questions [16].

That 'Weighted and more sophisticated systems such as TASH [Trauma-Associated Severe Hemorrhage] and PWH [Prince of Wales Hospital/Rainer] scores including higher numbers of variables perform superior over simple non-weighted models' is not that surprising [1]. On the contrary, a score that should be used in the emergency room has to be simple and quickly calculated. The search is always on for a good compromise between a high prospective value and the simplicity of calculation by developing new scores. This aspect is also important if we compare different scores. This article gives us full information about the established scores.

I hope Brockamp and colleagues' article will be read by many traumatologists and intensive care doctors. This article provides a great chance to learn more about scores, critical appraisal of trauma registries and hemorrhage management.

\section{Competing interests}

The author declares that he has no competing interests.
Published: 28 September 2012

References

1. Brockamp T, Nienaber U, Mutschler M, Wafaisade A, Peiniger S, Lefering R, Bouillon B, Maegele M; TraumaRegister DGU * Predicting on-going hemorrhage and transfusion requirement after severe trauma: a validation of six scoring systems and algorithms on the TraumaRegister DGU ${ }^{\bullet}$. Crit Care 2012, 16:R129.

2. Danks RR: Triangle of death. How hypothermia acidosis \& coagulopathy can adversely impact trauma patients. JEMS 2002, 27:61-66, 68-70.

3. Troidl H: Surgical Research. New York: Springer Verlag; 1998.

4. Gunning K, Rowan K: ABC of intensive care: outcome data and scoring systems. BMJ 1999, 319:241-244.

5. Oestern HJ, Kabus K: [Comparison of various trauma score systems. An overview]. Unfallchirurg 1994, 97:177-184.

6. Oestern HJ, Kabus K: [The classification of the severely and multiply injured - what has been established?]. Chirurg 1997, 68:1059-1065.

7. Baker SP, O'Neill B, Haddon W, Long WB: The injury severity score: a method for describing patients with multiple injuries and evaluating emergency care. J Trauma 1974, 14:187-196.

8. Tay S-Y, Sloan EP, Zun L, Zaret P: Comparison of the New Injury Severity Score and the Injury Severity Score. J Trauma 2004, 56:162-164.

9. Boyd CR, Tolson MA, Copes WS: Evaluating trauma care: the TRISS method. Trauma Score and the Injury Severity Score. J Trauma 1987, 27:370-378.

10. Matthes G, Seifert J, Bogatzki S, Steinhage K, Ekkernkamp A, Stengel D: [Age and survival likelihood of polytrauma patients. 'Local tailoring' of the DGU prognosis model]. Unfallchirurg 2005, 108:288-292.

11. Rixen D, Raum M, Bouillon B, Schlosser LE, Neugebauer E. Arbeitsgemeinschaft Polytrauma der Deutschen Gesellschaft für Unfallchirurgie: [Predicting the outcome in severe injuries: an analysis of 2069 patients from the trauma register of the German Society of Traumatology (DGU)]. Unfallchirurg 2001, 104:230-239.

12. Champion HR, Sacco WJ, Copes WS, Gann DS, Gennarelli TA, Flanagan ME: A revision of the Trauma Score. J Trauma 1989, 29:623-629.

13. Moore L, Lavoie A, LeSage N, Abdous B, Bergeron E, Liberman M, Emond M: Statistical validation of the Revised Trauma Score. J Trauma 2006, 60:305-311.

14. Kauvar DS, Lefering R, Wade CE: Impact of hemorrhage on trauma outcome: an overview of epidemiology, clinical presentations, and therapeutic considerations. J Trauma 2006, 60:S3-S11.

15. Surgeons ACO: ATLS: Advanced Trauma Life Support for Doctors (Student Course Manual). 8th edition. Chicago: American College of Surgeons; 2008.

16. TraumaRegister DGU ${ }^{\otimes}$ [www.traumaregister.de]

doi:10.1186/cc11514

Cite this article as: Raum MR: Validating scores: a good business for a

trauma register. Critical Care 2012, 16:159. 